\title{
On the reliability of the geomagnetic quake as a short time earthquake's precursor for the Sofia region
}

\author{
S. Cht. Mavrodiev \\ Institute for Nuclear Research and Nuclear Energy, Bulgarian Academy of Sciences, Sofia, Bulgaria \\ Received: 10 October 2003 - Revised: 16 March 2004 - Accepted: 17 March 2004 - Published: 21 June 2004
}

\begin{abstract}
The local "when" for earthquake prediction is based on the connection between geomagnetic "quakes" and the next incoming minimum or maximum of tidal gravitational potential. The probability time window for the predicted earthquake is for the tidal minimum approximately \pm 1 day and for the maximum \pm 2 days. The preliminary statistic estimation on the basis of distribution of the time difference between occurred and predicted earthquakes for the period 2002-2003 for the Sofia region is given.

The possibility for creating a local "when, where" earthquake research and prediction NETWORK is based on the accurate monitoring of the electromagnetic field with special space and time scales under, on and over the Earth's surface. The periodically upgraded information from seismic hazard maps and other standard geodetic information, as well as other precursory information, is essential.
\end{abstract}

\section{Introduction}

The problem of "when, where and how" earthquake prediction can't be solved only on the basis of geodetic data (Aki, 1995; Main, 1999a, b; Ludwin, 2001; Pakiser and Shedlock, 1995; Geller et al., 1997). The possible tidal trigging of the earthquakes has been investigated for a long period of time (Knopoff, 1964; Ryabl at al., 1968; Shlien, 1972; Molher, 1980, Sounau et al., 1982; Shirley, 1988, Bragin, 1999). The conclusion that the earthquake's time is correlated with the tidal extremums is not unique, because in some of the extremums there are no earthquakes.

The inclusion of additional information in the monitoring, for example, of the analysis of the Earth's electrical currents signals, permits one to estimate the most probable time of incoming earthquakes (Thanassoulas, 1991; Thanassoulas et al., 2001a, b).

Correspondence to: S. Cht. Mavrodiev

(mavrodi@inrne.bas.bg)
The more accurate space and time measuring set for the Earth's crust condition parameters, the including in the monitoring of the electromagnetic fields measurements under, on and over the Earth's surface, the temperature distribution and other possible precursors can be useful for the study of the "when, where and how" of an earthquake's prediction. For example, in the papers (Varotsos and Alexopoulos, 1984a, b; Varotsos at al., 1996; Geller, 1996), the possibility for shortterm earthquake prediction in Greece by seismic electric signals was investigated. The results of observations on seismoelectromagnetic waves at two earthquake experimental areas in China were presented in the paper of Qian at al. (1994).

The atmospheric and ionospheric electromagnetic phenomena associated with earthquakes were analyzed in many books and papers (Hayakawa and Fujinawa, 1994; Hayakawa et al., 1999, 2000; Hayakawa and Molchanov, 2002) and the future direction of the investigation related to earthquake prediction was proposed, as well as its practical application to some concrete events. The papers (Oike and Ogawa, 1982, 1994) concern the observations of electromagnetic radiation in the LF and VLF ranges related to the occurrence of an earthquake. The results of the complex investigation of the variations of crust electrical resistivity as a function of tidal deformations on the basis of extremely low frequency radio station, which permit the hope for an increase in the reliability of electromagnetic-based earthquake prediction, are presented in paper of Saraev et al. (2002).

Evidence in papers (Eftaxias 2001, 2002) is presented that electromagnetic anomalyties in wide range of radio frequencies from ULF, VLF to VHF have been observed before some destructive earthquakes in continental Greece.

The impressive results of the modified VAN method are presented in papers and via web sites (ws) (Thanassoulas, 1991; Thanassoulas et al., 1991, 1999, 2001a, b, c, d), where the appropriate measuring of electric Earth signals and their analysis demonstrates that the direction to the epicenter of incoming earthquakes can be estimated and the time is defined from the next extremum of tidal potential. Some possible geophysical models of the phenomena are proposed and the 


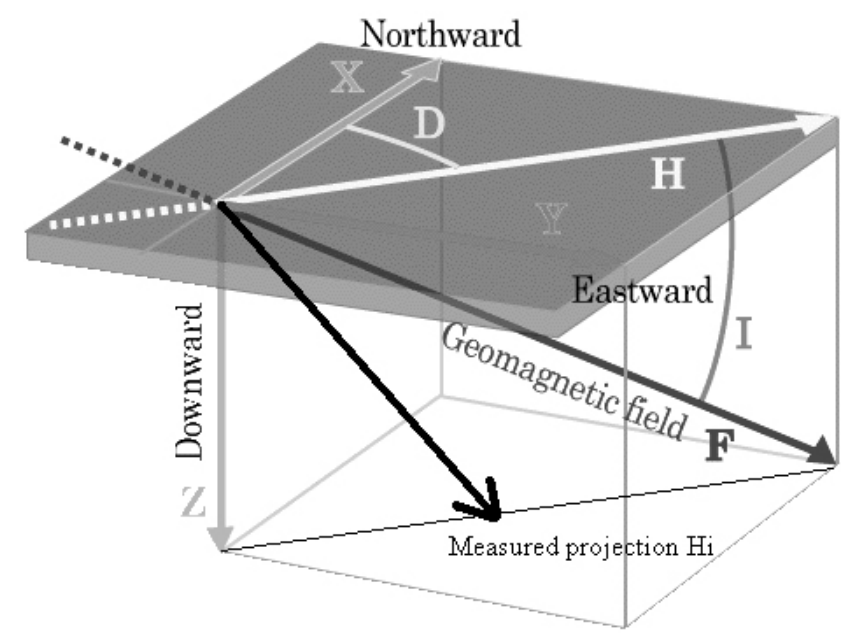

Fig. 1. The components of Earth's geomagnetic field (source: http: //swdcwww.kugi.kyoto-u.ac.jp/element/eleexp.html).

prediction of the future magnitude is analyzed. The inclusion of more than one site in the monitoring will permit short-term earthquake prediction and will give some estimation for the magnitude (Thanassoulas, 1999).

In web site (ws) (Ustundag, 2001) and papers cited there, the results of electropotential monitoring, based on the special constructed electrometer and appropriate temporal data acquisition system are presented, for researching the electropotential variations as an earthquake precursor.

One has to mention the satellite possibilities for monitoring the radiation activity of the Earth's surface for discovering the anomalies, which should be earthquake precursors: ws Dean (2003).

The analyses of the data from satellite monitoring for the ionosphere and the Earth's radiation belt parameters also give evidences for anomalies which can be interpreted as earthquake precursors. The information for the last results from the developing of earthquake precursor research could be found in the conference sites: Contadakis (2002) and Papadopoulos (2003).

The data for the connection between incoming earthquake and meteorology effects, like quasi-stationary earthquake clouds can be seen in the site Zhonghao Shou (1999). The statistic from 1993 for the reliability of prediction is also represented, together with some theoretical models and estimations for the effect.

In order to summarize the results, we can say that the standard geodetic monitoring (USGS Pf, ws, 2002; Pakiser and Shedlock, 1995) the monitoring of different components of electromagnetic field under, on and over the Earth's surface, some of the atmospheric anomalies and the behavior of charge distribution in the Earth's radiation belts (see, for example, Silina, 2001; Larkina and Ruzhin, 2003), sometime could serve as unique earthquake precursors. It is obvious that for solving the reliability problem different approaches should be unified, including the biological precursor data.

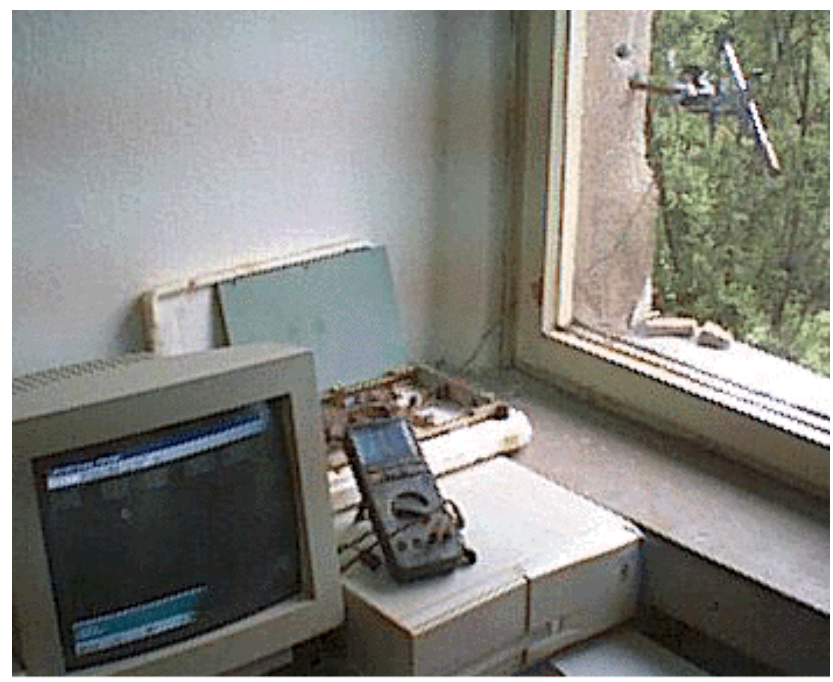

Fig. 2. The magnetometer with sensor and PC.

The progress in electromagnetic quake earthquake precursor approach (Mavrodiev and Thanassoulas, 2001) is presented (Mavrodiev, 2002a, b; 2003a, b, c). The approach is based on the understanding that earthquake processes have a complex origin. Without creating an adequate physical model of the Earth's existence, the gravitational and electromagnetic interactions, which ensure the stability of the Sun's system and its planets for a long time, the Earth's prediction problem cannot be solved. The earthquake part of the model can be repeated in the infinity way "theoryexperiment-theory", using nonlinear inverse problem methods looking for the correlations between fields in dynamically changed space and time scales. Of course, every approximate model (see, for example, Thanassoulas, 1991; Thanassoulas et al., 2001a, b) which has some experimental evidence has to be included in the analysis. It seems obvious that the problem of adequate physical understanding of the correlations between electromagnetic precursors, tidal extremums and incoming earthquakes is connected with the progress of the adequake Earth's magnetism theory.

The achievement of the Earth's surface tidal potential modelling, which includes the ocean and atmosphere tidal influences, is an essential part of the research. In this sense the comparison of the Earth tides analysis programs (Dierks and Neumeyer, ws) for the ANALYZE from the ETERNA-package, version 3.30 (Wenzel, 1996a, b), program BAYTAP-G in the version from 15 November 1999 (Tamura, 1991), Program VAV (version from April 2002) of Venedikov et al. (2001, 2003), is very useful.

The role of geomagnetic variations as a precursor could be explained by the obvious hypothesis that during the time before the earthquakes, the strain, deformation or displacement changes in the crust in some interval of density changing, where the chemical phase shift arrises which leads to an electrical charge shift. The preliminary Fourier analysis of geomagnetic field gives the time period of alteration in 

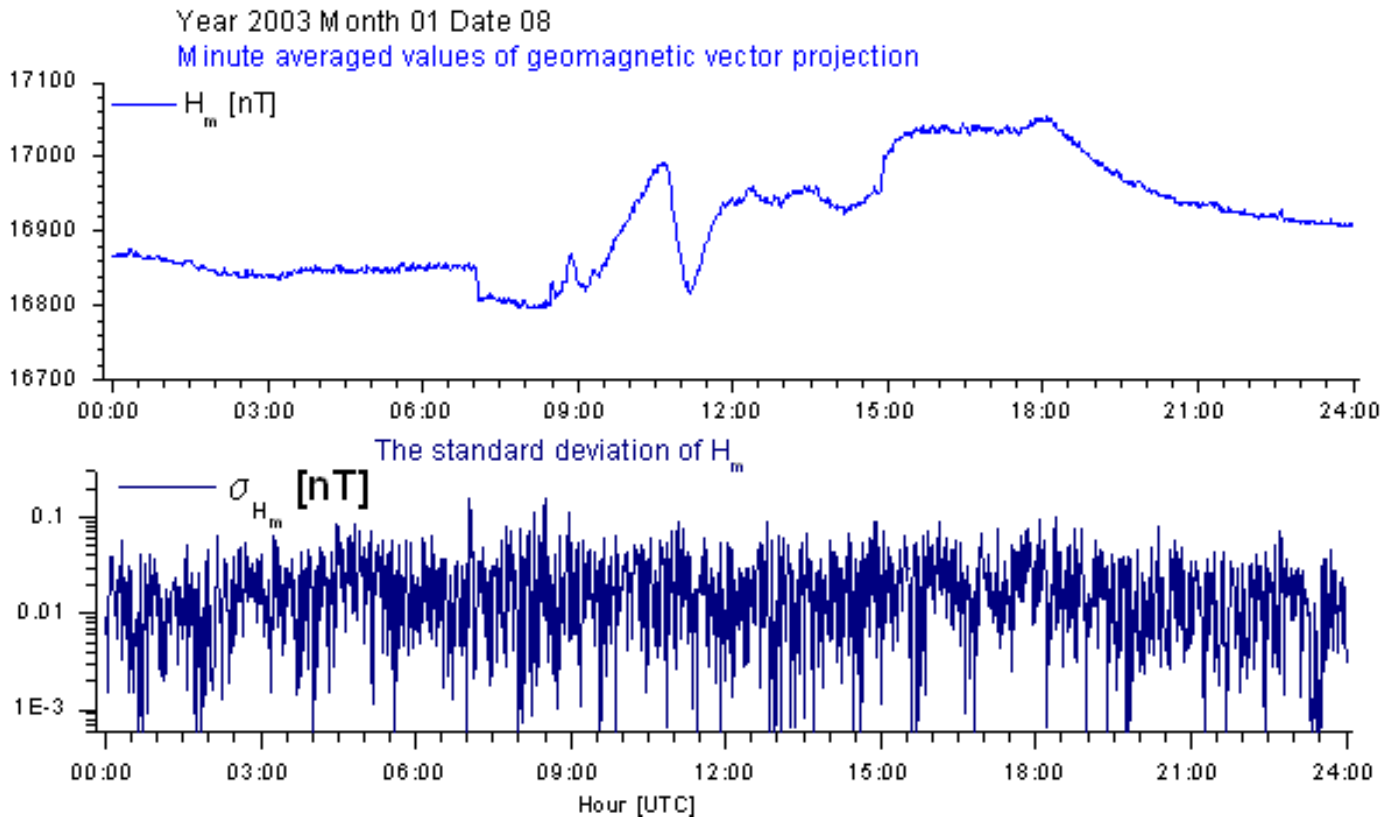

Fig. 3. The behaviour of geomagnetic field for a normal day.
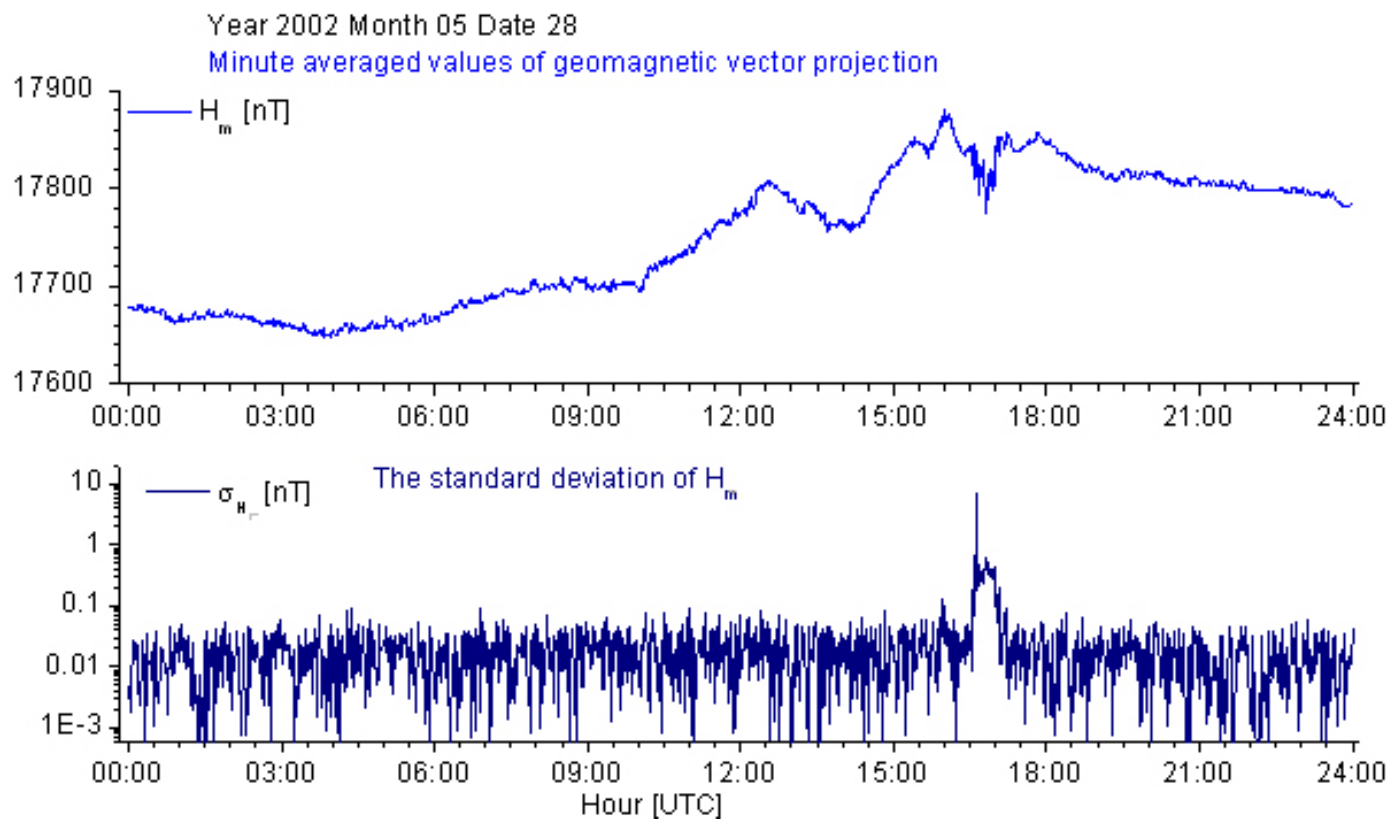

Fig. 4. The behaviour of geomagnetic field for a day with a signal for a near future earthquake.

minute scale. Such a specific geomagnetic variation is called a geomagnetic quake. The piezo-effect model for electrical currents cannot explain the alternations due to its linearity.

The K-index (Balsh, 2003), accepted for the estimation of the geomagnetic conditions, cannot indicate well the local geomagnetic variation for time minutes period, because it is calculated on the basis of 3-h data. Nevertheless, the Kindex behavior in the near space has to be analyzed because of the possible Sun-wind influence on the local behavior of the geomagnetic field. If the field components are measured many times per second, one can calculate the frequency de- pendence of full geomagnetic intensity and analyze the frequency spectrum of the geomagnetic quake. If the variations are bigger than usual for some period of time, one can say that we have the geomagnetic quake, which is the earthquake precursor. The nonlinear inverse problem analysis for 19992001 of geomagnetic and earthquake data for the Sofia region gives the estimation, that the probability time window for the predicted earthquake (event, events) is approximately \pm 1 day for the next minimum of Earth tidal potential and \pm 2 days for the maximum. 

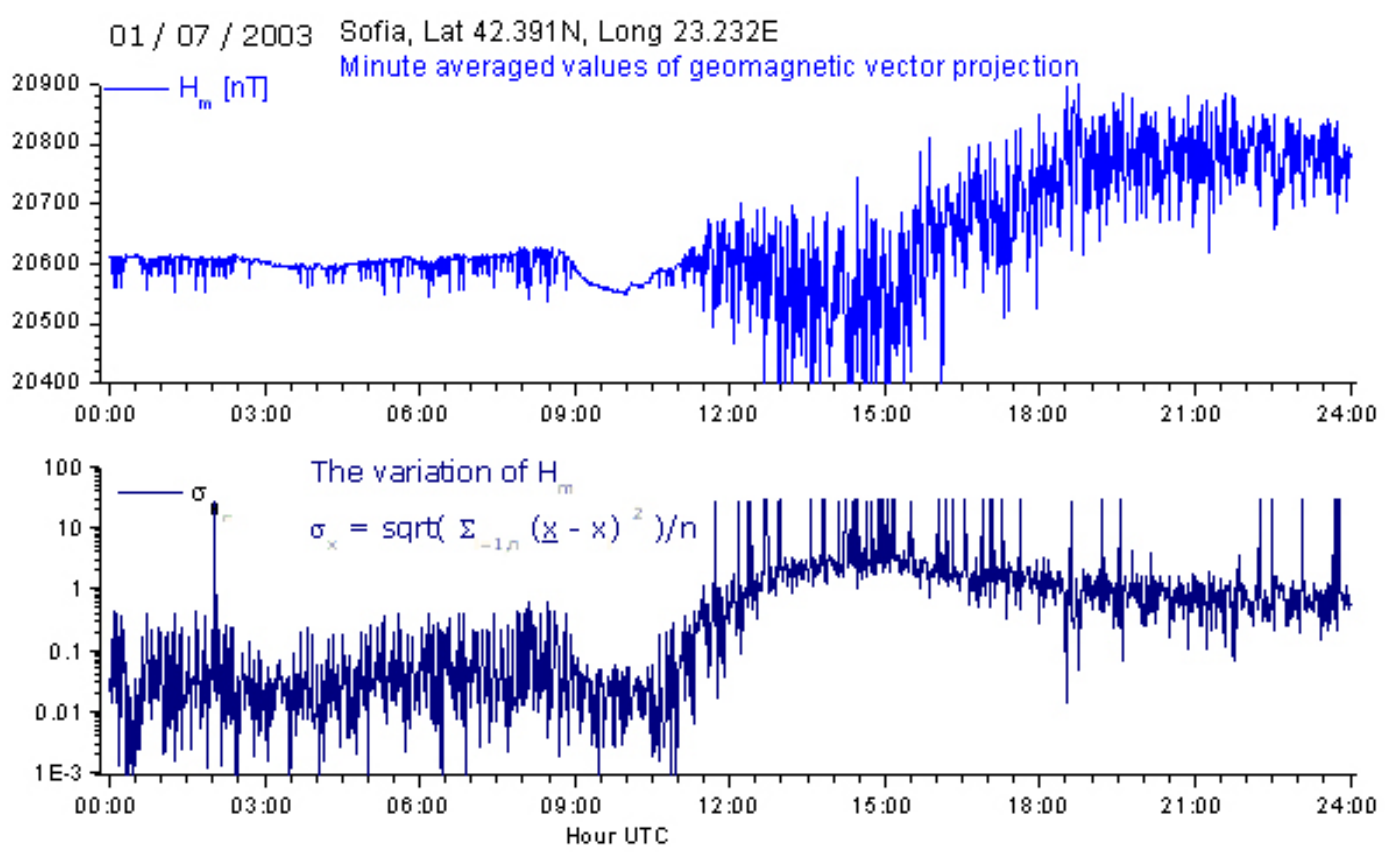

Fig. 5. A day with geomagnetic quake, which is precursor for more than one earthquake.

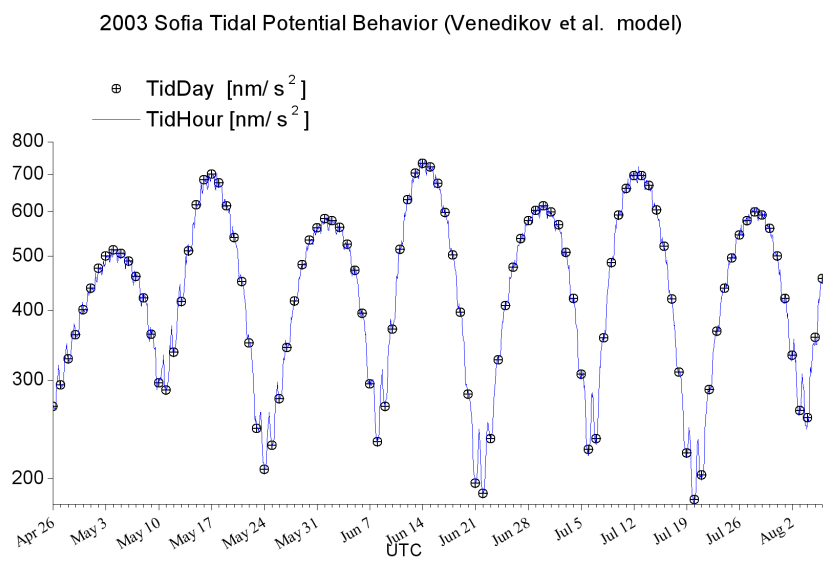

Fig. 6. The example of tital gravitational potencial behaviour, MayJune 2003, Sofia Lat $42.391^{\circ} \mathrm{N}$, Lon $23.232^{\circ} \mathrm{E}$.

The future epicenter coordinates could be estimated from the data from at least 3 points of measuring the geomagnetic vector, using the inverse problem methods, applied for the estimation of the coordinates of the volume, where the phase shift arrived in the framework of its time window.

In the case of an incoming big earthquake (magnitude $>5$ 6) the changes of vertical electropotential distribution, the Earth's temperature, the infrared Earth's radiation, the behavior of water sources, its chemistry and radioactivity, the atmosphere conditions (earthquakes clouds, etc.) and the charge density of the Earth's radiation belt, have to be dramatically changed near the epicenter area.

The achievements of tidal potential modeling of the Earth's surface, including ocean and atmosphere tidal influ- ences, multi-component correlation analysis and nonlinear inverse problem methods in fluids dynamics and electrodynamics, are crucial for every single step of the construction of the mathematical and physical models.

In Sect. 2 the 2002-2003 statistics estimations are given for the reliability of the time window earthquake prediction on the basis of geomagnetic field measurements (Mavrodiev, 2002b) and the Earth tidal behavior (Venedikov at al., 2002) for Sofia region.

In Sect. 3 the posterior analysis for the Alaska 2002, Magnitude 8.2 earthquake on the basis of seconds CMO geomagnetic data and for the Hokkaido 2003, MMB minute geomagnetic data is presented.

In Sect. 4 a short proposal for creating of short time earthquake prediction local NETWORK is given.

\section{The geomagnetic field quake as a time window earth- quake's precursor for Balkan, Black Sea region}

It is useful to stress that the author's interest in the earthquake prediction problem arises as a result of complex research of the Black Sea ecosystem about 15-20 years ago (Mavrodiev, 1998). During the time of gathering, the historical data for the ecosystem was observed, that the Crime earthquake, occurred in 1928, as an evidence for electromagnetic and earthquake correlations. Such a hypothesis has been proposed by the academician Popov in the early 20-30-ties of the last century (private communication).

According to the INTERMAGNET requirements (Geomagnetic data, 1986) for measuring the geomagnetic field (see Fig. 1) on the Earth's surface (http://www.intermagnet. org), the accuracy is $\pm 10 \mathrm{nT}$ for $95 \%$ of the reported data 
Table 1. The parameters of predicted events (Fig. 5).

\begin{tabular}{lccccccc}
\hline DD:MM:YY hh:mm & Latitude & Longitude & Dept $(\mathrm{km})$ & Magnitude & Distance $(100 \mathrm{~km})$ & $S_{\text {ChtM }}$ \\
\hline 03/07/2003 & $15: 49$ & 42.96 & 25.29 & 10 & 2.6 & 1.10 & 219 \\
03/07/2003 & $20: 51$ & 41.96 & 23.28 & 12 & 2.9 & 0.48 & 684 \\
$05 / 07 / 2003$ & $21: 58$ & 40.35 & 26.14 & 2 & 4.0 & 2.97 & 70 \\
$06 / 07 / 2003$ & $19: 10$ & 40.46 & 26.01 & 10 & 5.7 & 3.16 & 89 \\
$06 / 07 / 2003$ & $19: 39$ & 40.62 & 25.25 & 2 & 4.2 & 2.35 & 111 \\
$06 / 07 / 2003$ & $20: 02$ & 40.72 & 25.98 & 20 & 3.2 & 2.54 & 71 \\
$06 / 07 / 2003$ & $20: 10$ & 40.46 & 26.08 & 10 & 5.0 & 3.20 & 76 \\
$06 / 07 / 2003$ & $20: 48$ & 40.28 & 26.08 & 2 & 4.1 & 3.01 & 70 \\
$06 / 07 / 2003$ & $21: 58$ & 40.38 & 26.10 & 10 & 3.9 & 2.92 & 70 \\
$06 / 07 / 2003$ & $22: 05$ & 40.34 & 26.00 & 2 & 3.9 & 2.92 & 71 \\
$06 / 07 / 2003$ & $22: 42$ & 40.95 & 26.00 & 10 & 4.6 & 2.80 & 89 \\
$07 / 07 / 2003$ & $00: 24$ & 40.25 & 25.98 & 2 & 3.7 & 3.00 & 64 \\
$07 / 07 / 2003$ & $00: 48$ & 40.44 & 25.87 & 18 & 3.4 & 2.77 & 66 \\
$07 / 07 / 2003$ & $07: 15$ & 41.67 & 24.88 & 10 & 3.1 & 1.21 & 230 \\
$07 / 07 / 2003$ & $16: 17$ & 40.37 & 25.91 & 10 & 3.3 & 2.85 & 61 \\
$08 / 07 / 2003$ & $02: 48$ & 41.82 & 22.93 & 12 & 2.8 & 0.65 & 465 \\
$08 / 07 / 2003$ & $12: 00$ & 42.84 & 23.32 & 10 & 2.5 & 0.50 & 565 \\
\hline
\end{tabular}
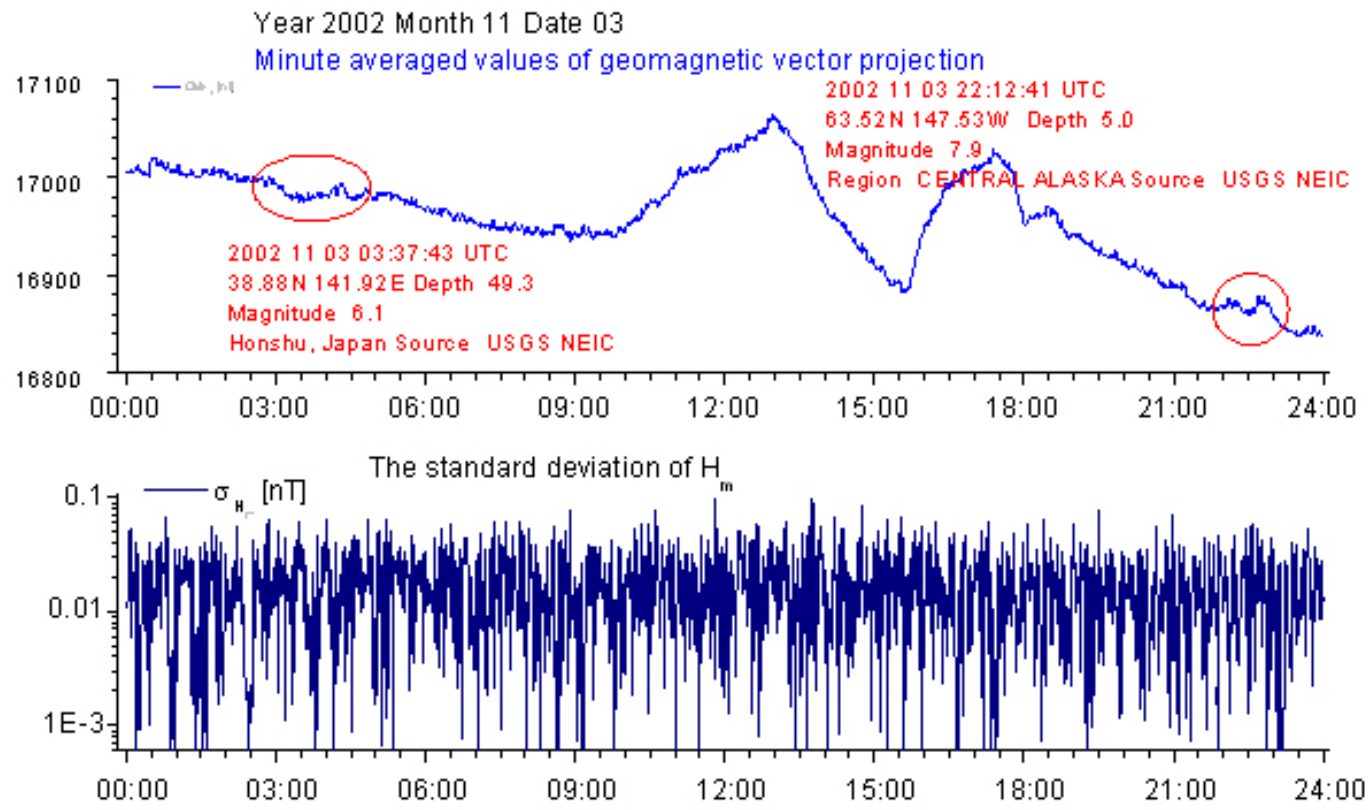

Fig. 7. A registration of big world earthquake, with magnitude $>6$.

and $\pm 5 \mathrm{nT}$ for the definitive data, with one sample per $5 \mathrm{~s}$, in the case of vector magnetometer ( $\boldsymbol{F}$ (XYZ) or $\boldsymbol{F}$ (HDZ)) and $1 \mathrm{nT}$, with 3 samples per second for Scalar Magnetometer $(\boldsymbol{F})$.

The geomagnetic vector projection $\boldsymbol{H}$ is measured with relative accuracy less or equal to $1 \mathrm{nT}$ by a fluxgate, feedback based device of a rather original and simple, but powerful construction. (know-how of JINR, Dubna, B. Vasiliev, 1998, private communication). It is used with 2.4 samples per second. Due to technical reasons the sensor was oriented under the horizon in a manner that the measured value of $\boldsymbol{H}$ at around $20000 \mathrm{nT}$ (see Figs. 1 and 2).

The minute averaged value $H_{m}$ and its error $\Delta \bar{H}_{M}$ are

$\bar{H}_{m}=\sum_{i=1}^{N_{m}} \frac{H_{i}}{N_{m}}$ and $\Delta \bar{H}_{m}=\sum_{i=1}^{n_{m}} \frac{\Delta H_{i}}{N_{M}}$,

where $H_{i}, \Delta H_{i}$ are the measured $N_{m}=144$ times per minute values of the field and their experimental error. The standard 
Reliability of EQ's Predictions for Jan-Mar 2003, Sofia, Lat 42.391N, Long 23.232E

The $S_{\text {ChtM }}$ and occurred earthquakes, $S_{\text {ChtM }}=2 \mathrm{Mag} /\left(R_{\text {eq }}+\text { Distance }\right)^{2}, R_{\text {eq }}=40+$ Dept/Mag $[\mathrm{km}]$. The vertical error of Mag is Distance [Hundred km], Blue - NEIC data, Black - GPhI, BAS, Sofia data. The signal for near eq is Sig irregularity. The time- next Tidal (Venedikov et al model) $\min (+/-1$ day) or max(+/-2 days). Control of reliability http://www.emsc-csem.org/. Data: http: //wwwneic.cr.usgs.gov/neis/bulletin/ and GPhI,BAS, Sofia

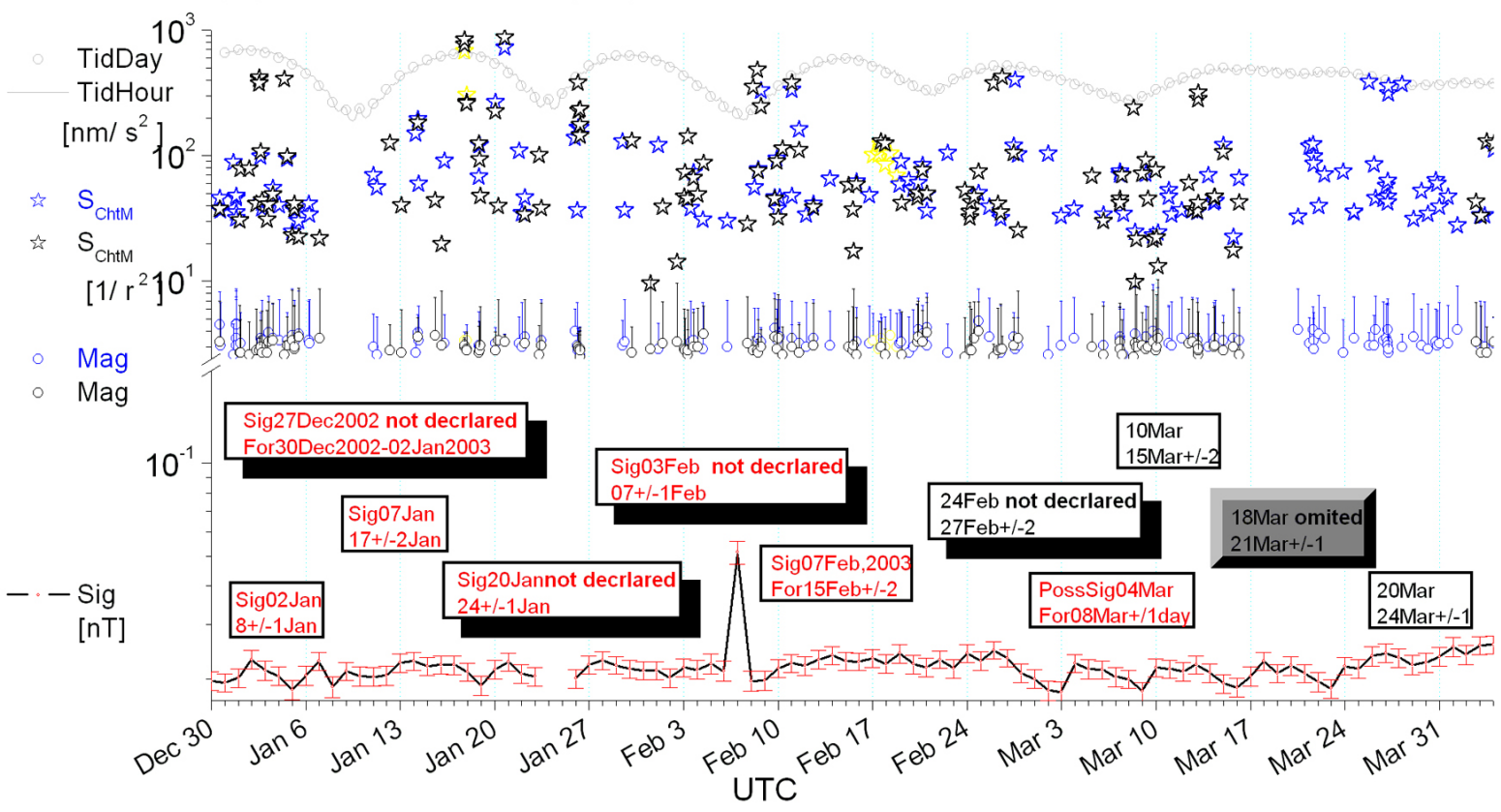

Fig. 8. The reliability of the time window prediction for incoming earthquake, January-March 2003, Sofia region.

\section{April - June, 2003 Time eq's prediction reliability Sofia, Lat42.391N, Lon23.232E}

The $\mathrm{S}_{\mathrm{chtM}}$ and occurred earthquakes, $\mathrm{S}_{\mathrm{ChtM}}=2 \mathrm{Mag} /\left(\mathrm{R}_{\mathrm{eq}}+\text { Distance }\right)^{2}, \mathrm{R}_{\mathrm{eq}}=40+\mathrm{Dept} / \mathrm{Mag}[\mathrm{km}]$. The vertical error of Mag is Distance [Hundred km], Blue - NEIC data, Black - GPhI, BAS, Sofia data. The signal for near eq is Sig irregularity. The time- next Tidal (Venedikov et al model) $\min (+/-1$ day) or $\max (+/-2$ days). Control of reliability http://www.emsc-csem.org/. Data: http: //wwwneic.cr.usgs.gov/neis/bulletin/ and GPhI,BAS, Sofia

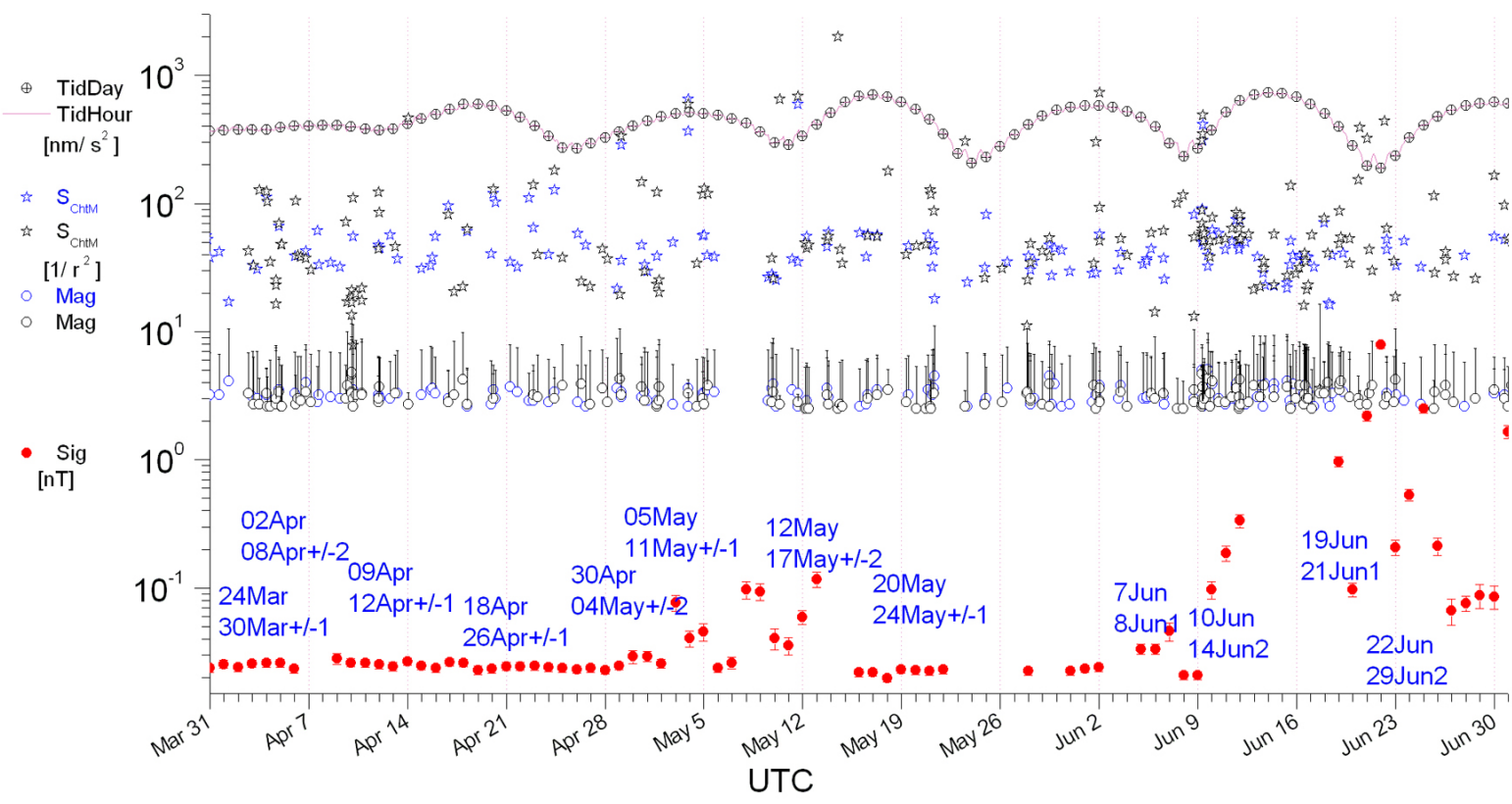

Fig. 9. The reliability of the time window prediction ofr incoming earthquake, April-June 2003, Sofia region. 
deviation $\sigma_{H_{m}}$ and its error $\Delta \sigma_{H_{m}}$ for every minute are

$\sigma_{H_{m}}=\frac{\sqrt{\sum_{i=1}^{N_{m}}\left(H_{i}-\bar{H}_{m}\right)^{2}}}{N_{m}}$ and

$\Delta \sigma_{H_{m}}=\frac{\sqrt{\sum_{i=1}^{N_{m}}\left(\Delta H_{i}-\overline{\Delta H_{m}}\right)^{2}}}{N_{m}}$.

Looking for the correlations between the behavior of the geomagnetic field, Earth tidal gravitational potential and the occurred earthquakes (from 1999 to 2001), it turns out that the daily averaged value of $\sigma_{H_{m}}$ and $\sigma_{\Delta H_{m}}$, which we denote by $\operatorname{Sig}(\Delta \mathrm{Sig})$, is playing the role of earthquake precursor.

Figure 3 illustrates the behavior of the geomagnetic field component and its variation for a period without earthquake precursors in the region. Figures 4 and 5 illustrate the behavior of the geomagnetic field and its variation, which is unusual. In this case there is a geomagnetic quake which is the precursor for the incoming event (earthquake or earthquakes). One has to be sure that there are no cosmos or Sun wind reasons for the geomagnetic quake (see the sites NOAA, ws).

For example, in Fig. 4 the predicted time window was $3 \pm 1$ June 2002 and the prediction was confirmed with an earthquake occurring on 3 June 2002, 02:04, Lat $41.95^{\circ} \mathrm{N}$, Lon $23.10^{\circ}$ E, Dep 8, Mag 2.6, Ml, $50 \mathrm{~km}$ from Sofia, $S_{\mathrm{ChtM}}=598$ $\left[\mathrm{Mag} / \mathrm{r}^{2}\right]$.

The preliminary Fourier analysis of $H_{m}$ data gives the fact that the bigger geomagnetic variations are caused by the arrival for hours time period of new frequencies, with periods from a 10th of a s until 10th of a min and with very specific amplitude behavior. Such spectrum, which arrives for hour periods of time, is invisible for minute samples measuring. Its almost real-time Fourier analysis is very complicated and there are some digital evidences that the arrived electromagnetic field cannot have a linear piezo effect explanation.

The probability time window of the incoming event (or events) is defined by the next date of the Earth's tidal potential extremum, with tolerance approximately for the tidal minimum of \pm 1 day and for the maximum of \pm 2 days.

The uncertainty of distinguishing the predicted event (or group of events - for example, aftershocks) from the events which occurred in the region at different distances and magnitudes in the predicted time window, is solved on the basis of inverse problem methods with the new earthquake influence characteristic function $S_{\mathrm{ChtM}}$ :

$S_{\mathrm{ChtM}}=\frac{2 \text { Magnitude }}{\left(R_{e q}+D i s \tan c e\right)^{2}}$,

$R_{e q}=0.040+\frac{\text { Dept }}{\text { Magnitude }}[1000 \mathrm{~km}]$.

The physical sense of the function $S_{\mathrm{ChtM}}$ is a density distribution on the Earth's surface of the earthquake's magnitude (magnitude vs. distribution). In the point of measurement $S_{\mathrm{ChtM}}$ is logarithmically proportional to the energy influence of the earthquakes. It is important to point out that the first consideration of the magnitude and distance dependences was obtained on the basis of nonlinear inverse problem methods. Obviously, the nearer and biggest earthquake (relatively biggest value of $S_{\mathrm{ChtM}}$ ) will bear more electropotential variations, which will generate more power geomagnetic quakes. At this stage of the study, as a measure of daily geomagnetic state there is the value of averaged for $24 \mathrm{~h}$ (1440 min) standard deviation $\sigma_{H_{m}}$ :

$\operatorname{Sig}=\sum_{i=1}^{1440} \frac{\sigma_{H_{m}}}{1440}, \Delta \operatorname{Sig}=\sum_{i=1}^{1440} \frac{\Delta \sigma_{H_{m}}}{1440}$.

The simple and usually working criterion for evidence of a geomagnetic quake is when Sig increases for two consecutive days $i, i+1$ and the differences between the values of Sig are bigger than the mean arithmetic sum of their errors $\Delta \mathrm{Sig}$ :

$\operatorname{Abs}\left(\operatorname{Sig}_{i+1}-\operatorname{Sig}_{i}\right)>\left(\Delta \operatorname{Sig}_{i}+\Delta \operatorname{Sig}_{i+1}\right) / 2$.

If criteria (2) are fulfilled and there are no cosmos or Sungenerated variations of geomagnetic field, it could be concluded that a geomagnetic quake has happened. Such a quake is a unique precursor for an incoming earthquake and in the next minimum or maximum of the local tidal gravitational potential somewhere in the region, this predicted earthquake will occur.

For some of the cases, criteria (2) have to be calculated for decades of hours or tens of minutes.

The signal is observed for earthquakes with different epicenters in the case when the specific behavior of a field and its standard deviation occurs more than once per day at different hours.

The analysis of the precursor function Sig on the basis of special digital 5-point derivatives can serve in the future for creating the algorithm for an automated alert system.

It is obvious that a more detailed time window can be achieved by analyzing the daily variations of tidal potential, calculated every hour.

As an example, the parameters of predicted events (Fig. 5) are presented in Table 1.

At this stage of the study all earthquakes have the same $S_{\text {ChtM }}$ for different definitions of the magnitude. After the developing of mathematical models of empirical and theoretical dependences between incoming earthquake processes, magnetic quake and parameters of earthquakes on the basis of an inverse nonlinear problem we will obtain a set of $S_{\mathrm{Cht}}$ functions in correspondence with the different definitions of magnitude. The volumes, its depth, the chemical and geological structures of the region have to be included in the dependences as well.

Figure 7 illustrates the possibility for registration of big world earthquakes by specific behavior of the geomagnetic change.

In Figs. 8, 9, 10 and 11 the tidal potential, $S_{C h t M}$, magnitude, distance from Sofia and function Sig are presented for 
The $S_{\text {chtm }}$ and occurred earthquakes, $S_{\text {Chtm }}=2 \mathrm{Mag} /\left(R_{\text {eq }}+\text { Distance }\right)^{2}, R_{\text {eq }}=40+$ Dept/Mag [km]. The vertical error of Mag is Distance [Hundred km], The signal for near eq is Sig irregularity. The time- next Tidal (Venedikov et al model) minimum (+/-1 day) or $\max (+/-2$ days). Control of reliability http://www.emsc-csem.org/. Data: http: //wwwneic.cr.usgs.gov/neis /bulletin/ and GPhI,BAS, Sofia. In Blue- the confirmed date.

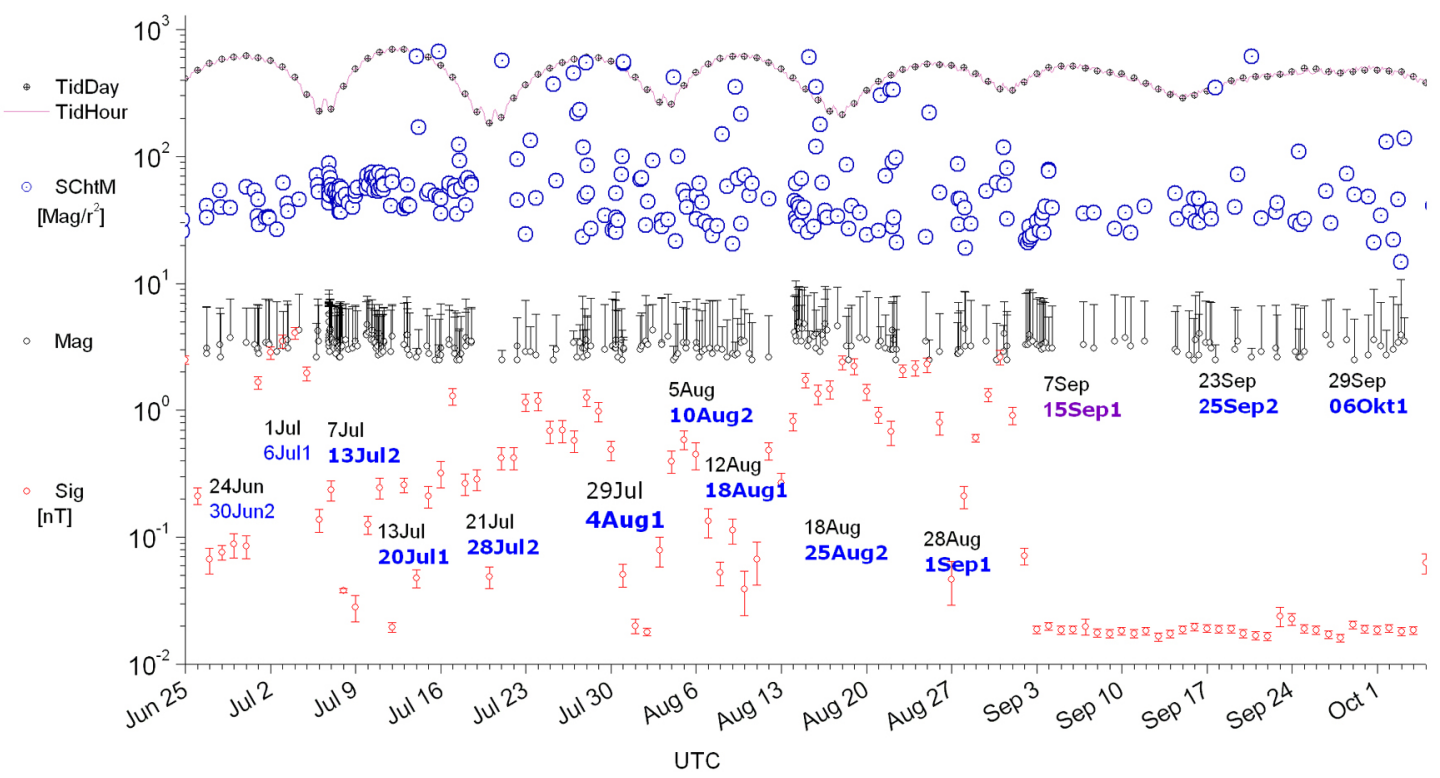

Fig. 10. The reliability of the time window prediction ofr incoming earthquake, July-September 2003, Sofia region. Distance [Hundred km], The signal for near eq is Sig irregularity. The time- next Tidal (Venedikov et al model) minimum (+/-1 day) or $\max (+/-2$ days). Control of reliability http://www.emsc-csem.org/. Data: http: //wwwneic.cr.usgs.gov/neis /bulletin/ and GPhI,BAS, Sofia. In Blue- the confirmed date.

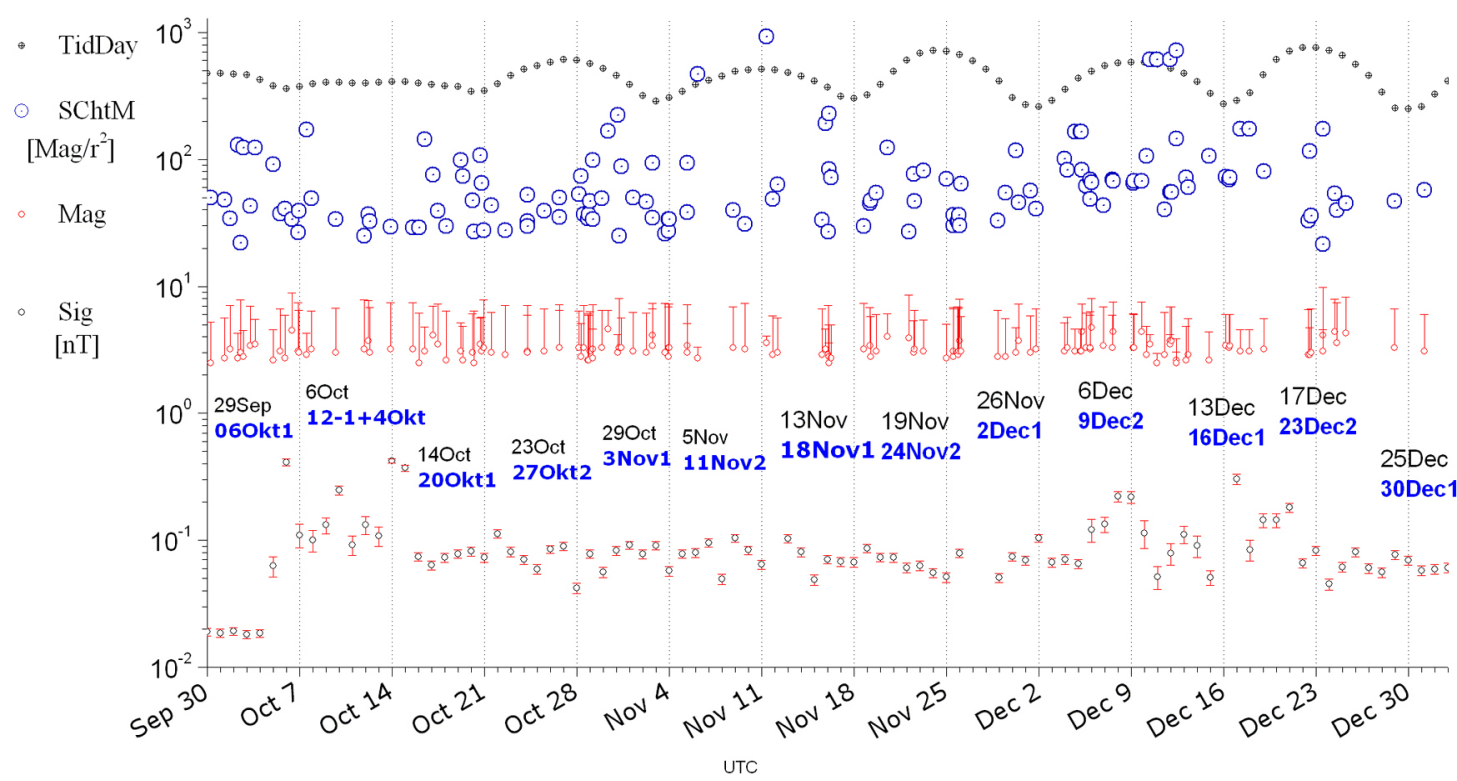

Fig. 11. The reliability of the time window prediction ofr incoming earthquake, October-December 2003, Sofia region. 


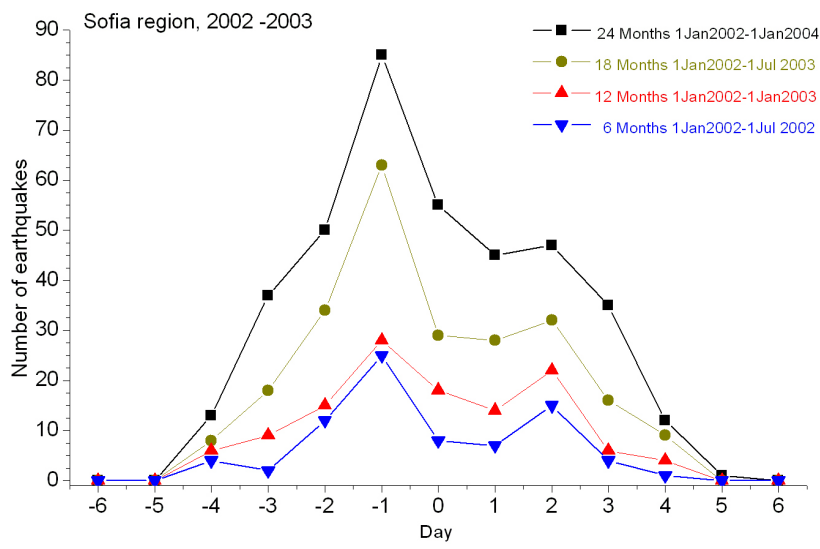

Fig. 12. The distributions of difference between predicted time and the time of occurred earthquakes for 6, 12, 18 and 24 months.

every quarter of 2003. In the text boxes are the data of the geomagnetic quake (date of the precursory signal) and the time window for predicted event (events).

In Fig. 12 the distributions of the difference between the times of predicted events, which occurred, calculated for 6 , 12, 18 and 24 months (starting from January 2002), are presented. The distribution growth, without widening and its approximation to the Gaussian distribution with the time, is an argument for the causality-consequences origin between the correlation geomagnetic signal-tidal potential extremum and the occurred earthquake. The number of earthquakes in Fig. 12 is greater than the number of the predictions for the events. The explanation of this is that some earthquakes with greater magnitude are following by aftershocks.

In Fig. 13 the distributions of the difference between times of all occurred earthquakes in the region (distance less than $500 \mathrm{~km}$ ), magnitude greater than 2.6 and the corresponding tidal extremums time, calculated for 6, 12, 18 and 24 months (starting from January 2002), as well the comparison with Fig. 12, are presented. The fact that the distributions of all earthquakes are flatter than the distributions of predicted earthquakes can be consider as evidence that the correlation between geomagnetic quake and tidal extremum in the framework of physical mean of function $S_{\mathrm{ChtM}}$ is a reliable precursor.

Next, Fig. 14 expresses the obvious fact that the incoming earthquake with greater magnitude can be predicted at greater distances. Nowadays estimation is that bigger earthquakes (magnitude $>5$ ) could be predicted for distances up to $500-600 \mathrm{~km}$.

In Fig. 15 the magnitude distribution of the predicted 380 events is represented. It could be seen that the earthquakes with magnitude less than 3 are a small part (26\%) of all predicted and occurred earthquakes.

The independent control (in the framework of Strasbourg recommendations about earthquake prediction of the European Union for ethical and public security reasons) of the time window earthquake prediction reliability was organized in the framework of the Bulgarian Academy of Sciences, its Geophysical Institute and colleagues from Greece and Turkey, who are interested in this topic of research (Tsatsaragos, ws; Ustundag, ws), starting from January 2002.

As a conclusion, from the observations for the analyzed period 2002-2003 there were 110 extremums of tidal potential and 96 events (total number of earthquakes: 486 for 2002 and 552 for 2003). For 85 of them the time window was successfully predicted. For two of the occurred events the precursor quake was not established (in the first month of the reported time period) by the everyday analysis and 9 events were not predicted because of a hardware problem. The total number of earthquakes with magnitude greater than 2.5 was 1038. The epicenter of the incoming event cannot be estimated using one point geomagnetic data, so one can not number the really predicted earthquakes. But there are visible correlations between hazard risk estimation map (Giardini et al., 2003) and Fig. 16.

The above results for reliability time window earthquake prediction can be consider as a first preliminary step for a solution of "when, where and how" earthquake prediction at level "when", using the geomagnetic measurements.

The first prove that, in the framework of such complex approach, the "when, where and how" earthquake prediction problem can be solved for the "when, where" prediction on the basis of at least 3 points for electromagnetic real-time monitoring is the essential. If the statistic estimation is successful for a long enough period of time (6-12 months) and the established correlations are confirmed by the adequate physical model solutions, one could say that the earthquake prediction problem could be solved using the geomagnetic quake precursor.

\section{The posteriori analysis}

\subsection{Alaska, 2002 Magnitude 8.2 earthquake, Seconds CMO geomagnetic data}

In the case of geomagnetic vector measurements the precursor signal Sig is defined as the daily averaged sum of normalized standard deviations

$\frac{\sigma_{\bar{H}_{m}}}{\bar{H}_{m}}, \frac{\sigma_{\bar{D}_{m}}}{\bar{D}_{m}}, \frac{\sigma_{\bar{Z}_{m}}}{\bar{Z}_{m}}$ (Fig. 17).

The minute averaged second HDZ Alaska, College, CMO geomagnetic observatory data and their normal standard deviations for 23 October-8 November 2002 are presented in Fig. 17. The data for tidal daily behavior, function $S_{\mathrm{ChtM}}$, the magnitude of occurred earthquakes and precursor signal Sig are presented in Fig. 18 for the period from 24 October to 9 November 2002. The precursor Sig is calculated using the second HDZ College Geomagnetic observatory data (CMO Intermagnet geomagnetic observatory with coordinates $64.84^{\circ} \mathrm{N}, 148.86^{\circ} \mathrm{W}$ ).

Although the geomagnetic data are only seconds, the correlation between the geomagnetic precursor function and incoming earthquake is clearly seen for 3 events, including the 


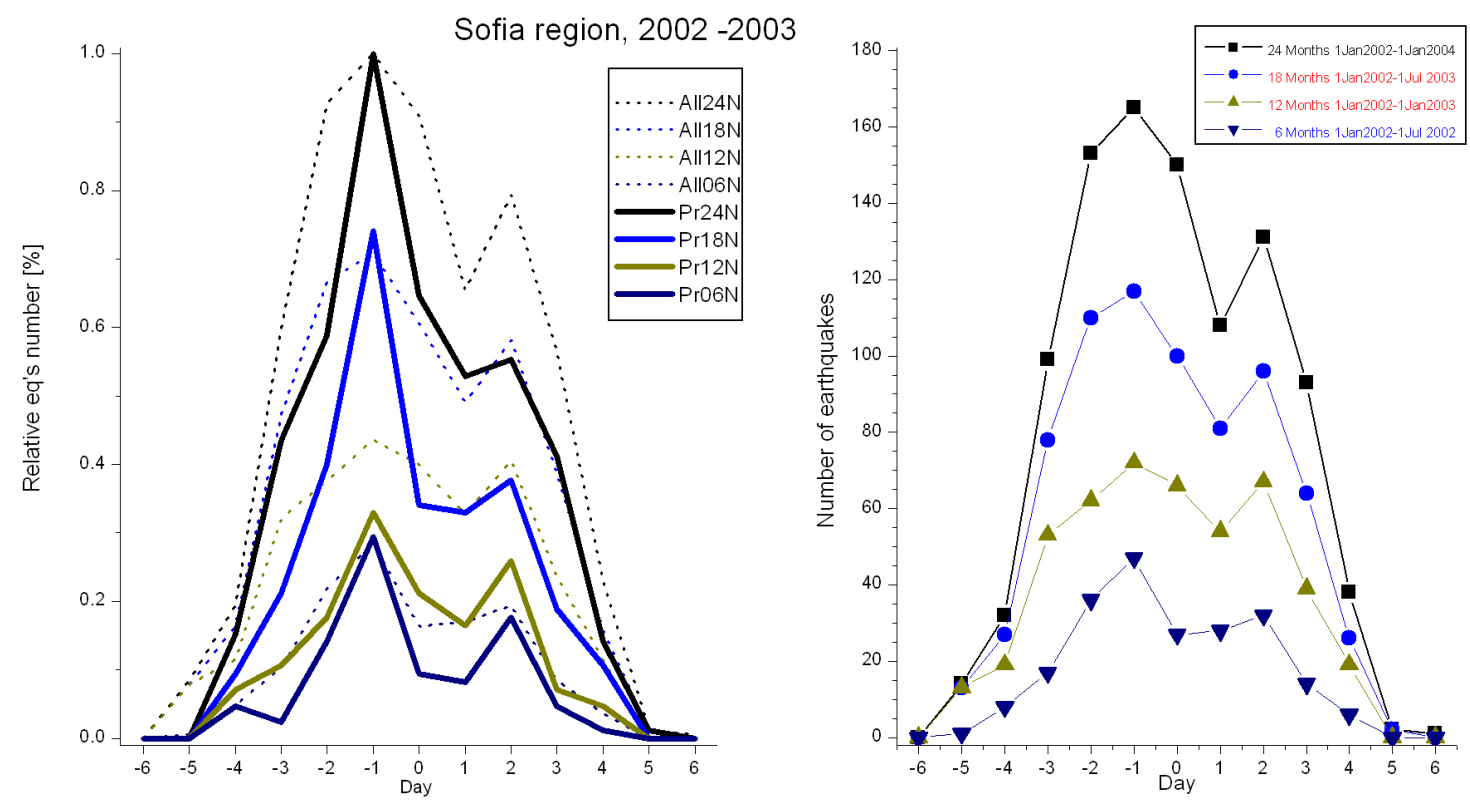

Fig. 13. Left: the normal distributions of the difference between tidal extremums' time and the time of the predicted (solid curves) and all (dotted) occurred earthquakes for 6,12, 18 and 24 months. Right: the distributions of the difference between tidal extremums' time and the time of all occurred earthquakes for $6,12,18$ and 24 months.

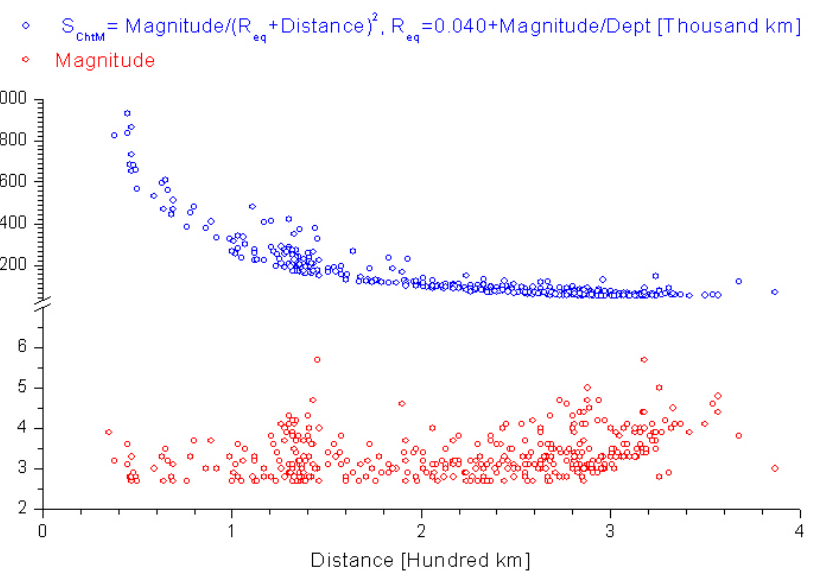

Fig. 14. The $S_{\mathrm{ChtM}}$ function and magnitude for predicted and occurred earthquakes, Sofia region, 2002-2003.

big earthquake with magnitude $=8.5$. The second CMO geomagnetic data were kindly given by the USA Intermagnet group.

\subsection{Hokkaido 2003, MMB minute geomagnetic data}

The preliminary analysis on the basis of the Sofia region experience of the second MMB Intermagnet data shows that the Hokkaido could be a good polygon for testing the possibility for the "when, where" prediction, if two more Intermagnet geomagnetic sites $\boldsymbol{F}(\mathrm{HDZ})$ with at least 10 samples per second will be created.

Analogous analysis for the regions where there are Intermagnet geomagnetic stations for establishing the correlation

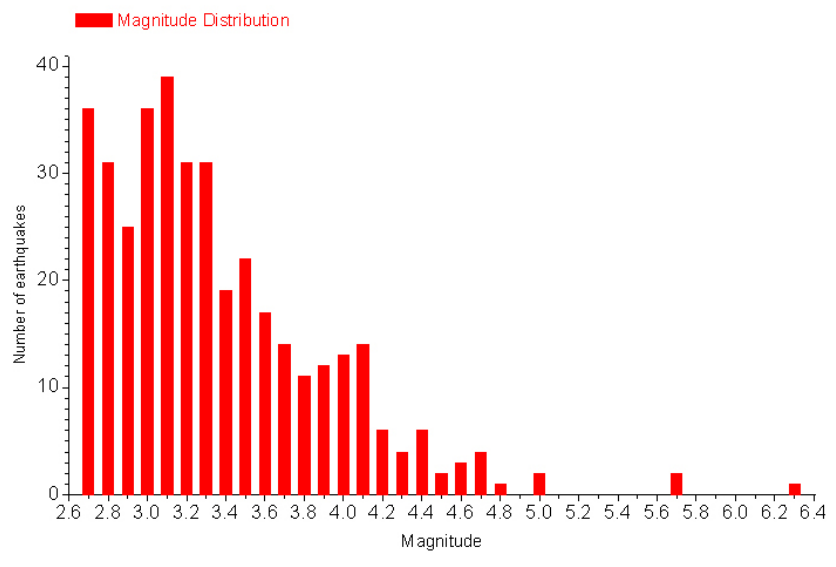

Fig. 15. The distribution of magnetitude for predicted and occurred earthquakes, Sofia region, 2002-2003.

between a local geomagnetic quake and an incoming are, in the time window defined from the time of the next minimum or maximum of the tidal behavior and earthquakes, was performed for England, India, Turkey (Mavrodiev, 2003a, b).

\section{Proposal for creating of short time earthquake pre- diction local NETWORK}

We will not discuss the long time prognostic system for estimation of earthquake risk. According to Keilis-Borok (ws) and Giardini et al. (2003), they are well known.

The aim of this paper is to create a system for study of the reliability of the local forecast system for earthquakes in the 


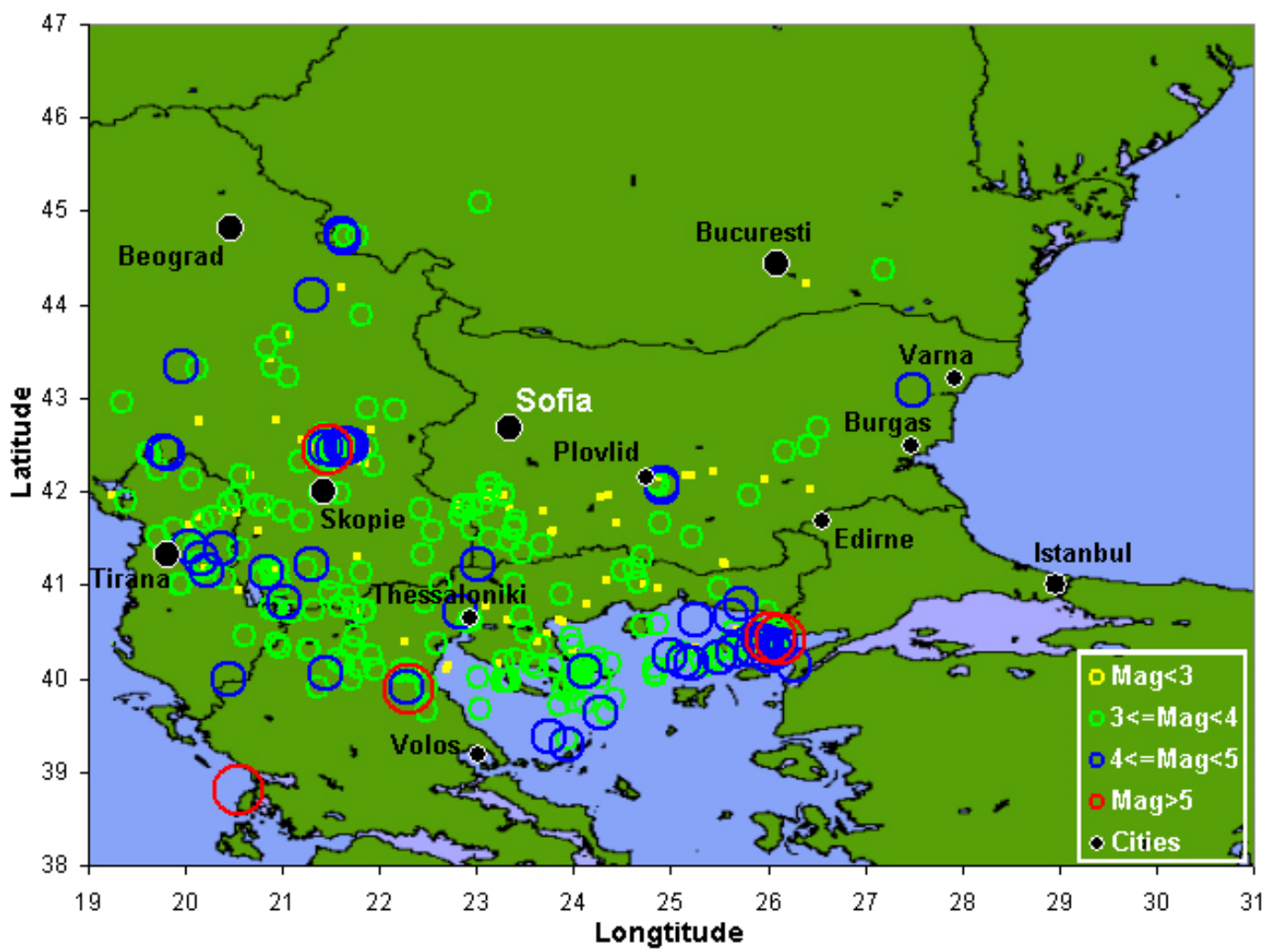

Fig. 16. Map of epicenters for earthquakes which occurred in the predicted time window, Sofia region, 2002-2003.

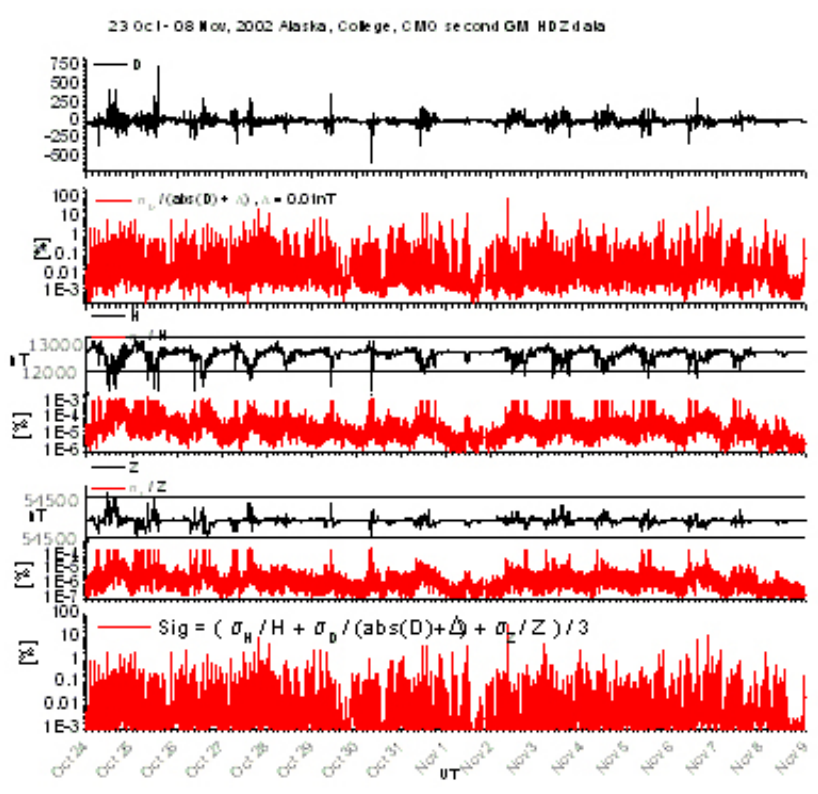

Fig. 17. The minute averaged second HDZ data and their normal standard deviation, 23 October-8 November 2002.

interval Mag $>2.6-3$ with radius up to $600 \mathrm{~km}$. The system is complex and the attended practical result will be a short time "when, where" prediction. The problem "when, where and how" will be solved step-by-step in creating an adequate physical theoretical model for the Earth's magnetism. For such complex research a new type of scientific unification has to be realized, including experimental, theoretical and technological parts.

\subsection{Experimental data}

Experimental data includes geomagnetic field, the atmospheric and ionospheric electromagnetic phenomena in wide range of radio frequencies from ULF, VLF to VHF, electropotential distribution in the Earth's crust and atmosphere, temperature Earth crust distribution, crust parameters (strain, deformation, displacement), gravitational anomaly map, season and day independent depth temperature distribution, water source parameters (debit, temperature, chemical composition, radioactivity), gas emissions, ionosphere condition parameters, infrared radiation of Earth's surface, earthquake clouds, Earth radiation belt, Sun wind, biological precursors.

\subsection{Theory}

The achievements of tidal potential modeling of the Earth's surface, including ocean and atmosphere tidal influences, multi-component correlation analyses, nonlinear inverse problem methods in fluids dynamics and Maxwell equations, are crucial. 
23 October- 16 November, 2002 Alaska region

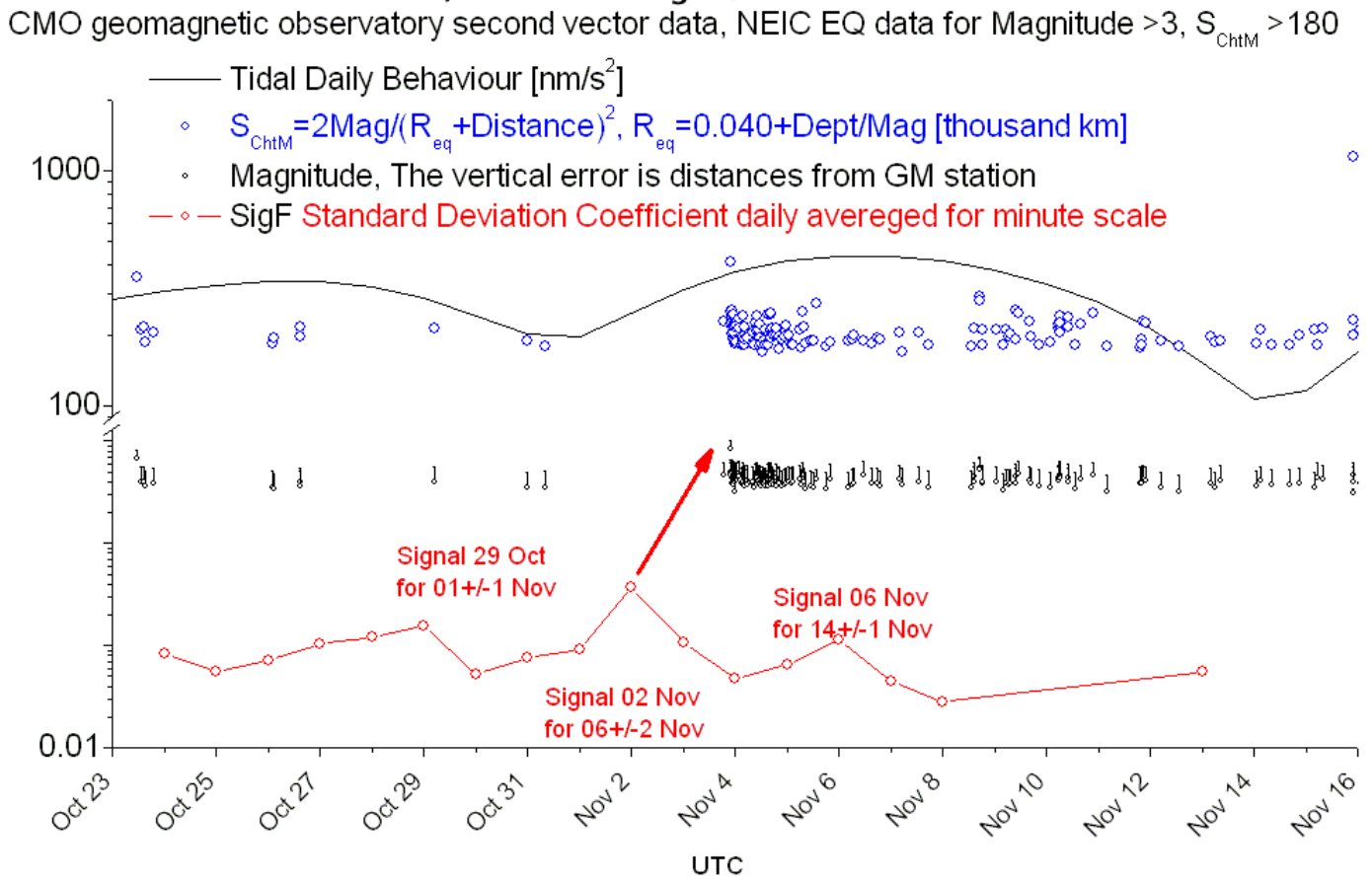

Fig. 18. The correlation between geomagnetic variations $\left(\operatorname{Sig}_{F}\right)$. Tidal potential extremums, local maximum of function $S_{\mathrm{ChtM}}$ and time of occurred earthquake illustrated with Alaska 11 March 2003, 22:12, Lat 63.517, Lon - 147.444. Dep 4.9, Mag 8.5 earthquake.

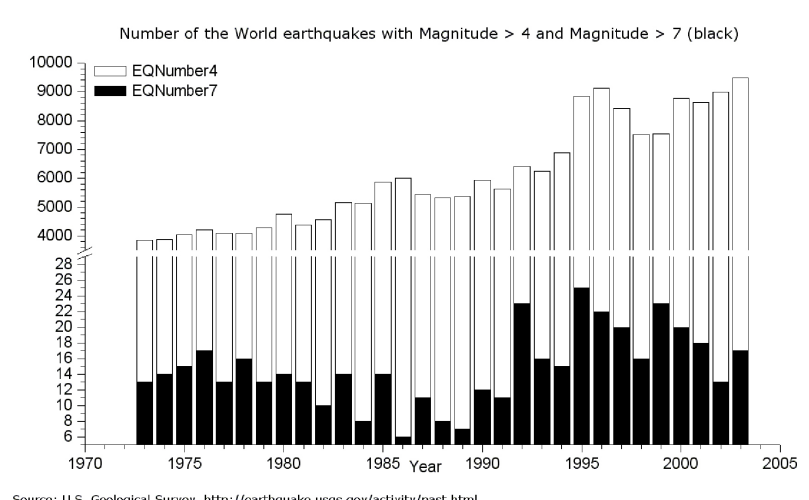

Fig. 19. The number of world earthquakes with magnitude $>4$ and 7 from 1972.

\subsection{Technologies}

The using of GIS and data acquisition systems for archiving, analysis, visualization and interpretation of the data in almost real time and non- linear inverse problem methods for step by step creating and testing the theoretical models for the parameters behavior, correlations and dynamics in the framework of wide interdisciplinary scientific group are necessary but not sufficient conditions for the successful working research and prediction NETWOK.

The set of the devices used has to be in correspondence with known data for earthquake risk zones (gravitational anomalies, crust parameters' monitoring-strain, deformation, displacement and seismic hazard evaluation maps). The geomagnetic device set distance has to be $150-200 \mathrm{~km}$, the electropotential from 100 to $200 \mathrm{~km}$ in accordance with the present geological situation and its history. The set for monitoring the daily and season crust temperatures has to be in the range of $100 \mathrm{~km}$. The correlations with Sun wind influence have to be estimated in real time.

The system has to be created step by step. The condition for the next step has to be build on physically clear, new theoretical correlations or dynamical models and, of course, the successful "when", "when, where" or "when, where and how" earthquake predictions.

Finally, the number of the world earthquakes with a magnitude greater than 4 are represented in Fig. 19. The correlation between the earthquake number, global warming and subsequent increasing of the sea level and the amplitude of ocean tides is obvious. The possible explanation is in the fact that the global warming, because of ice decreasing, is a reason for perturbation of the momentum equilibrium of the Earth and of the ocean tidal amplitudes increasing. So, the continents' movements are activated in such manner that the number of earthquakes increase. The fact that the number of earthquakes with a magnitude grater than 7 conserve chaotic character can be interpreted as a chance that we still have some time to stop global warming and to prevent incoming anthropogenic geodetic disasters. 

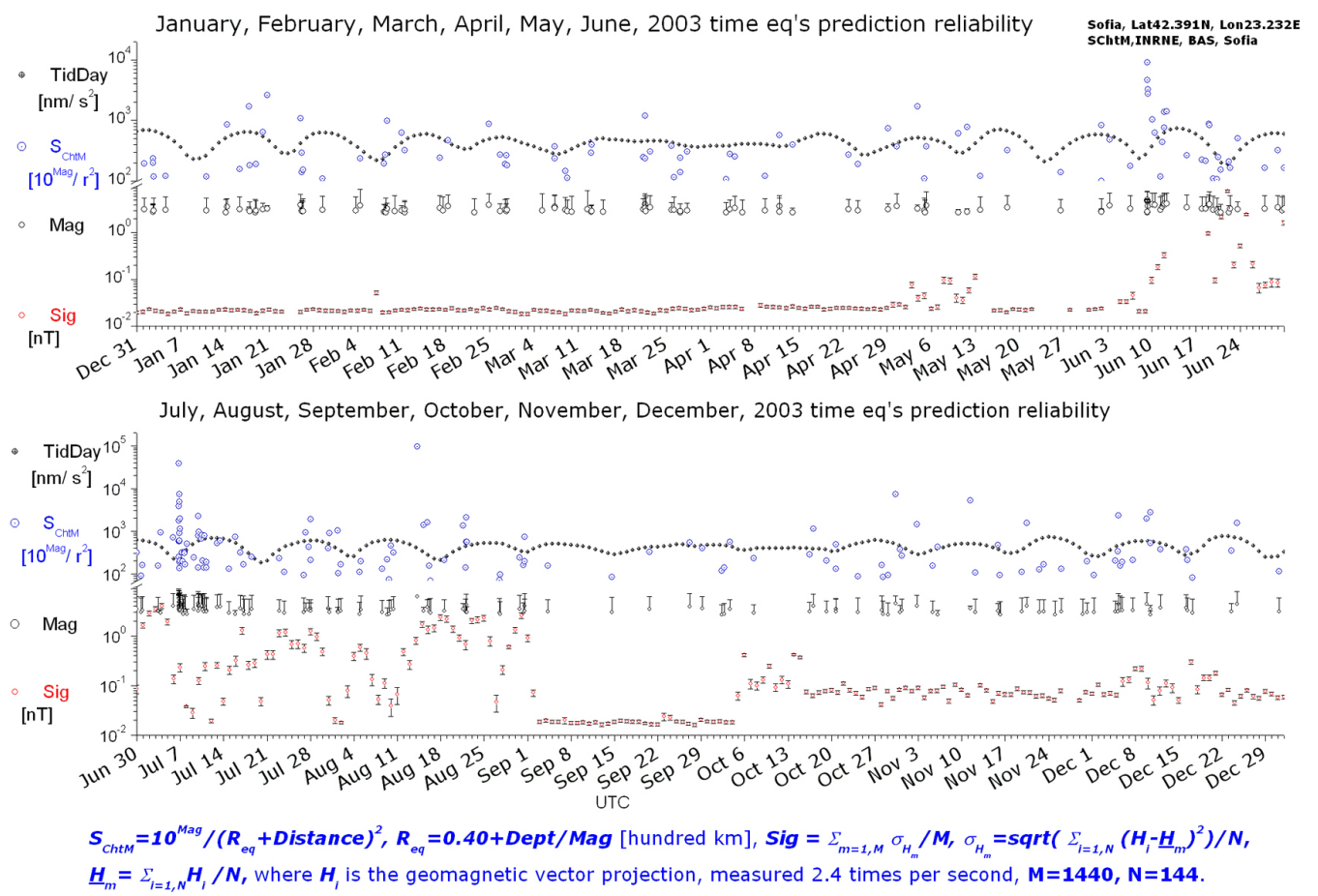

Fig. 20. The earthquake precursor (geomagnetic quake) is Sig irregularity. The vertical error of Mag is distance (100 km). The approximate time window for incoming event is defined from the next tidal potential (Venedikov et al. model) minimum ( \pm 1 day) or maximum $( \pm 2)$. Earthquake data from http://wwwneic.cr.usgs.gov/neis/bulletin/, GPhI, BAS, Sofia. Reliability time control http://www.emsc-csem.org/.

\section{Conclusions}

The correlations between the local geomagnetic quake and incoming earthquakes, which occur in the time window defined from tidal minimum ( \pm 1 day) or maximum ( \pm 2 days) of the Earth's tidal gravitational potential, are tested statistically. The distribution of the time difference between predicted and occurred events is going to be Gaussian with the increasing of the statistics. This result can be interpreted as a possible first reliable approach for solving the "when" earthquakes prediction problem using the geomagnetic data.

On the basis of electromagnetic monitoring under, on and over the Earth's surface research for the solution of the "when, where" earthquake prediction problem is proposed. Under the hypothesis that the current, which gave rise to the geomagnetic quake, has a bigger vertical component, the data of two geomagnetic vector devices are enough for the determination of the future epicenter. Three devices will permit one to study the correlation between Earth surface distribution of precursor function Sig and the magnitude of the incoming earthquake.

In Fig. 20 the reliability test for time prediction is presented, using the new, with more clearly physical mean, $S_{\text {ChtM }}$ function (Energy/squared distance) for 2003.
Acknowledgements. Thanks to B. Vasiliev, JINR, Dubna for magnetometer, A. Venedikov for Tidal cod VAV, E. Botev for GPhI, BAS, Sofia almost real time earthquake data, J. Love for Alaska, College second geomagnetic data, INRNE, BAS, Sofia for support, C. S. Mavrodiev, J. Tsatsaragos, A. Damianova and many other colleagues, including the editor and referees for help, interest, education, critical and constructive discussions.

Edited by: M. Contadakis

Reviewed by: two referees

\section{References}

Aki, K.: Earthquake prediction, societal implications, Univ. Southern California, From Reviews of Geophysics, http://www.agu. org/revgeophys/aki00/aki00.html, 1995.

Bragin, Y. A., Bragin, O. A., and Bragin, V. Y.: Reliability of Forecast and Lunar Hypothesis of Earthquakes, Report at XXII General Assembly of the International Union of Geodesy and Geophysics (IUGG), Birmingham, UK, 18-30 July 1999.

Balsh, C.: http://www.sel.noaa.gov/info/Kindex.html, 2003.

Contadakis, M., Biagi, P., and Zschau, J.: Seismic hazard evaluation, precursory phenomena and reliability of prediction, 27th EGS General Assembly, Nice, France, http://www.copernicus. org/EGS/EGS.html, 2002.

Dean, R.: www.earthquakeforecast.org, 2003.

Dierks, O. and Neumeyer, J.: Comparison of Earth Tides Analysis Programs, Geo Forschungs Zentrum Potsdam, Division 1, Telegrafenberg, 14473 Potsdam, Germany, http://www.ksb.be/ICET/ bim/text/dierks.htm, 2002. 
Eftaxias, K., Kapiris, P., Polygiannakis, J., Bogris, N., Kopanas, J., Antonopoulos, G., Peratzakis, A., and Hadjicontis, V.: Signature of pending earthquake from electromagnetic anomalies, Geophys. Res. Lett., 28, 17, 3321-3324, 2001.

Eftaxias, K., Kapiris, P., Dologlou, E., Kopanas, J., Bogris, N., Antonopoulos, G., Peratzakis, A., and Hadjicontis, V.: EM anomalies before the Kozani earthquake: A study of their behaviour through laboratory experiments, Geophys. Res. Lett., 29, 8, 10.1029/2001 GL013786, 2002.

Geller, R. J., Jackson, D. D., Kagan, Y. Y., and Mulargia, F.: Earthquakes cannot be predicted, Science, http://scec.ess.ucla.edu/ $\backslash \%$ 7Eykagan/perspective.html, 1997.

Geller, R. J.: Debate on evaluation of the VAN method: Editor's introduction, Geophys. Res. Lett., 23(11), 1291-1294, 10.1029/96GL00742, 1996.

Geomagnetic data: Intermagnet, http://www.intermagnet.org/ Data_e.html, ttp://geomag.usgs.gov/frames/mag_obs.htm, http://swdcwww.kugi.kyoto-u.ac.jp/wde/Sec3.html, http: //www.intermagnet.org/Magobs_e.html, 1986.

Giardini, D., Jiménez, M.-J., and Gruntha, G.: The ESC-SESAME Unified Hazard Model for the European-Mediterranean Region, EMSC/CSEM, Newsletter, 19, 2-4, 2003.

Hayakawa, M. and Fujinawa, Y. (Eds.): Electromagnetic Phenomena Related to Earthquake Prediction, Terrapub, Tokyo, 677, 1994.

Hayakawa, M., Fujinawa, Y., Evison, F. F., Shapiro, V. A., Varotsos, P., Fraser-Smith, A. C., Molchanov, O. A., Pokhotelov, O. A., Enomoto, Y., and Schloessin, H. H.: What is the future direction of investigation on electromagnetic phenomena related toearthquake prediction?, in: Electromagnetic phenomena related to earthquake prediction, edited by Hayakawa, M. and Fujinawa, Y., Terrapub, Tokyo, 667-677, 1994.

Hayakawa, M. (Ed.): Atmospheric and Ionospheric Electromagnetic Phenomena Associated with Earthquakes, Terrapub, Tokyo, 996, 1999.

Hayakawa, M., Ito, T., and Smirnova, N.: Fractal analysis of ULF geomagnetic data associated with the Guam eartquake on $8 \mathrm{Au}-$ gust 1993, Geophys, Res. Lett., 26, 2797-2800, 1999.

Hayakawa, M., Itoh, T., Hattori, K., and Yumoto, K.: ULF electromagnetic precursors for an earthquake at Biak, Indonesia oin 17 February 1996, Geophys, Res. Lett., 27, 10, 1531-1534, 2000.

Hayakawa, M. and Molchanov, O. (Eds.): Seismo Electromagnetics Lithosphere-Atmosphere-Ionosphere coupling, Terrapub, Tokyo, 477, 2002.

Karakelian, D., Klemperer, S. L., Thompson, G. A., and FraserSmith, A. C.: In review. Proc. 3rd conf. "Tectonic problems of the San Andreas Fault", Stanford, CA, 2001.

Karakelian, D., Klemperer, S. L., Fraser-Smith, A. C., and Beroza, G. C.: A Transportable System for Monitoring Ultralow Frequency Electromagnetic Signals Associated with Earthquakes, Seismo-logical Research Letters, 71, 4, 423-436, 2000.

Keilis-Borok, V. I.: http://www.mitp.ru, 2000.

Klemperer, S., Fraser-Smith, T., Beroza, G., Karakelian, D.: Stanford University, Ultra-low frequency electromagnetic monitoring within PBO, http://www.scec.org/news/00news/images/ pbominiproposals/Klempererpbo40.pdf.

Knopoff, L.: Earth tides as a triggering mechanism for earthquakes, Bull. Seism. Soc. Am., 54, 1865-1870, 1964.

Larkina, V. I. and Ruzhin, Yu. Ya: Wave Satellite Monitoring of Earthquake Precursors in the Earth Plasmasphere, in 1st International Workshop on Earthquake Prediction, Subcommission on Earthquake Prediction Studies (SCE) of the European Seis- mological Commission scheduled, Athens, Greece, http://www. gein.noa.gr/services/Workshop.htm, 2003.

Ludwin, R. S.: Earthquake Prediction, Washington Geology, 28, 3, 27, 2001.

Main, I.: Is the reliable prediction of individual earthquakes a realistic scientific goal?, Debate in Nature, http://www.nature.com/ nature/debates/earthquake/equake_contents.html, 1999a.

Main, I.: Earthquake prediction: concluding remarks, Nature debates, Week 7, 1999b.

Mavrodiev, S. Cht.: Applied Ecology of the Black Sea, ISBN 156072-613-X, 207 Pages, Nova Science Publishers, Inc., Commack, New York 11725, 1998.

Mavrodiev S. Cht.: The electromagnetic fields under, on and up Earth surface as earthquakes precursor in the Balkans and Black Sea regions, http://www.arXiv.org, physics, Subj-class: Geophysics; Atmospheric and Oceanic Physics, http://arXiv.org/abs/ 0202031, 2002a.

Mavrodiev, S. Cht.: On the short time prediction of earthquakes in Balkan-Black Sea region based on geomagnetic field measurements and tide gravitational potential behavior, http://arXiv.org/ abs/physics/0210080, 2002b.

Mavrodiev, S. Cht.: The electromagnetic fields under, on and over Earth surface as "when, where and how" earthquake precursor, Workshop on Gujarat Earthquake, Kanpur, India, http://www. arxiv.org/ftp/physics/papers/0302/0302033.pdf, 2003a.

Mavrodiev, S. Cht.: The electromagnetic fields under, on and over Earth surface as "when, where and how" earthquake precursor, European Geophysical Society, Geophys. Res. Abs., 5, 04049, $2003 b$.

Mavrodiev, S. Cht. and Thanassoulas, C.: Possible correlation between electromagnetic earth fields and future earthquakes, INRNE-BAS, Seminar proceedings, 23-27 July 2001, Sofia, Bulgaria, ISBN 954-9820-05-X, http://arXiv.org/abs/physics/ $0110012,2001$.

Molher, A. S.: Earthquake/Earth tide correlation and other features of the Susanville, California, earthquake sequence of June-July 1976, Bull. Seism. Soc. Am., 70, 1583-1593, 1980.

NEIC: http://wwwneic.cr.usgs.gov/neis/bulletin/, http://www. emsc-csem.org/, http://www.iris.edu/quakes/eventsrch.htm, http://www.geophys.washington.edu/seismosurfing.html.

NOAA: http://www.sec.noaa.gov/SWN/, http://www.sec.noaa.gov/ rt_plots/satenv.html, http://www.sec.noaa.gov/rt_plots/xray_5m. html.

Oike, K. and Ogawa, T.: Observations of electromagnetic radiation related with the occurrence of earthquake, Annu. Rep. Desaster, Prev. Res. Inst. Kyoto Univ., 25, B-1, 89-100, 1982.

Oike, K. and Yamada, T.: Relationship between shallow earthquakes and electromagnetic noises in the LF and VLF ranges, in: Electromagnetic phenomena related to earthquake prediction, edited by Hayakawa, M. and Fujinawa, Y., Terrapub, Tokyo, 115-130, 1994.

Pakiser, L. and Shedlock, K. M.: Predicting earthquakes, USGS, http://earthquake.usgs.gov/hazards/prediction.html, 1995.

Papadopoulos, G.: 1st International Workshop on Earthquake Prediction, Subcommission on Earthquake Prediction Studies (SCE) of the European Seismological Commission scheduled, Athens, Greece, November 2003, http://www.gein.noa.gr/ services/Workshop.htm, 2003.

Qian, S., Yian, J., Cao, H., Shi, S., Lu, Z., Li, J., and Ren, K.: Results of observations on seismo-electromagnetic waves at two earthquake experimental areas in China, in: Electromagnetic phenomena related to earthquake prediction, edited by 
Hayakawa, M. and Fujinawa, Y., Terrapub, Tokyo, 205-211, 1994.

Ryabl, A., Van Wormer, J. D., Jones, A. E.: Triggering of micro earth-quakes by earth tides and other features of the Truckee, California, earthquake sequence of September 1966, Bull. Seism. Soc. Am., 58, 215-248, 1968.

Saraev, A. K., Pertel, M. I., and Malkin, Z. M.: Correction of the electromagnetic monitoring data for tidal variations of apparent resistivity, J. Appl. Geophys., 49, 91-100, 2002.

Shlien, S.: Earthquake - tide correlation, Geophys. J. R. Astr. Soc., 28, 27-34, 1972.

Shirley, J.: Lunar and Solar periodicities of large earthquakes: Southern California and the Alaska Aleutian Islands seismic region, Geophys. J., 92., 403-420, 1988.

Silina, A. S., Liperovskaya, E. V., Liperovsky, V. A., and Meister, C.-V.: Ionospheric phenomena before strong earthquakes, Nat. Haz. Earth Sys. Sc., 1, 113-118, 2001.

Sounau, M., Sounau, A., and Gagnepain, J.: Modeling and detecting interaction between earth tides and earthquakes with application to an aftershock sequence in the Pyrenees, Bull. Seism. Soc. Am., 72, 165-180, 1982.

Tamura, Y., Sato, T., Ooe, M., and Ishiguro, M.: A procedure for tidal analysis with a Bayesian information criterion, Geophys. J. Int., 104, 507-516, 1991.

Thanassoulas, C.: Determination of the epicentral area of three earthquakes (Ms $>6 \mathrm{R})$ in Greece, based on electrotelluric currents recorded by the VAN network., Acta Geophysica Polonica, XXXIX, 4, 373-387, 1991.

Thanassoulas C., Earthquake prediction based on electrical signals recorded on ground surface - An integrated methodology answering on "where", "when" and "of what magnitude" a large EQ will occur, http://www.earthquakeprediction.gr/, 1999.

Thanassoulas, C., Tsatsaragos, J., and Klentos, V.: Determination of the most probable time of occurrence of a large earthquake, Open File Report A. 4338, IGME, Athens, Greece, 2001a.

Thanassoulas, C. and Klentos, V.: Very short-term ( \pm 1 day, $\pm 1 \mathrm{~h}$ ) time-prediction of a large imminent earthquake, the second paper, Institute of Geology and Mineral Exploration (IGME), Athens, Greece, Open File Report A. 4382, 1-24, 2001 b.

Thanassoulas, C. and Klentos, V.: The "energy-flow mo-del" of the Earth's lithosphere, Its application on the prediction of the "magnitude" of an imminent large earthquake, the third paper, Institute of Geology and Mineral Exploration (IGME), Athens, Greece, Open file report: A.4384, 1-20, 2001c.
Thanassoulas, C. and Klentos, V." The "energy-flow mo-del" of the Earth's lithosphere, its application on the prediction of the "magnitude" of an imminent large Earthquake, The "third paper", Institute of Geology and Mineral Exploration (IGME), Athens, Greece, Open File Report A. 4384, 1-20, 2001d.

Tsatsaragos, J.: Predicting earthquakes, (with Thanassoulas, C. till 2002), http://users.otenet.gr/ bm-ohexwb/alert2.htm, 1999.

USGS Pf: The Parkfield Experiment - Capturing What Happens in an Earthquake http://geopubs.wr.usgs.gov/fact-sheet/fs049-02/, 2002.

Ustundag, B.: Earthquake Forecast, Data Acquisition and Evaluation Page, http://www.deprem.cs.itu.edu.tr/, 2001.

Varotsos, P. and Alexopoulos, K.: Physical properties of the variations of the electric field of the Earth preceding earthquakes, I, Tectonophysics, 110, 93-98, 1984a.

Varotsos, P. and Alexopoulos, K.: Physical properties of the variations of the electric field of the Earth preceding earthquakes, II, Tectonophysics, 110, 99-125, 1984b.

Varotsos, P. and Alexopoulos, K.: Physical properties of the variations of the electric field of the Earth preceding earthquakes, I, Tectonophysics, 110, 93-98, 1984a.

Varotsos, P. and Alexopoulos, K.: Physical properties of the variations of the electric field of the Earth preceding earthquakes, II, Tectonophysics, 110, 99-125, 1984b.

Varotsos, P., Lazaridou, M., Eftaxias, K., Antonopoulos, G., Makris, J., and Kopanas, J.: Short-term Earthquake Prediction in Greece by Seismic Electric Signals, in: A Critical Review of VAN: Earthquake prediction from Seismic Electric Signals, edited by Ligthhill, Sir J., World Scientific Publishing Co., Singapore, 29-76, 1996.

Venedikov, A. and Arnoso, R.: Program VAV/2000 for Tidal Analysis of Unevenly Spaced Data with Irregular Drift and Colored Noise, J. Geodetic Society of Japan, 47, 1, 281-286, 2001.

Venedikov, A. P., Arnoso, R., and Vieira, R.: A program for tidal data processing, Computer \& Geoscience's, 29, 4, 487-502, 2003.

Wenzel, H.-G.: The nanogal software: Earth tide data processing package ETERNA 3.30, in: Marees Terrestres Bulletin d'Informations, edited by Melchior, P., Bruxelles: Association Internationale de Géodésie, 124, 9425-9439, 1996a.

Wenzel, H.-G.: ETERNA Manual, Version 3.30, Karlsruhe, Black Forest Observatory, 1996b.

Zhonghao, Shou: Earthquake Clouds and Short Term Prediction, http://quake.exit.com/, 1999. 